\title{
An Analysis of Court Imposed Monetary Sanctions in Seattle Municipal Courts, 2000-2017.
}

Report Prepared For:

The City of Seattle, Office for Civil Rights

$7 / 28 / 2020$

Prepared by:

Frank Edwards

Assistant Professor

School of Criminal Justice

Rutgers University

frank.edwards@rutgers.edu

Alexes Harris

Professor

Department of Sociology

University of Washington

yharris@uw.edu

Acknowledgements: We are grateful to the assistance of Caedmon Magboo Cahill, City of Seattle Office for Civil Rights for her support in framing this study and to Rich Cook, Seattle Municipal Court's Research, Policy and Planning Group for his assistance with accessing the data used in this report. 


\section{Lists of Tables and Figures}

\begin{tabular}{|c|c|}
\hline Table 1. & $\begin{array}{l}\text { Median annual total SMC LFOs by case type (in } 2018 \text { inflation adjusted } \\
\text { dollars). }\end{array}$ \\
\hline Table 2. & Distribution of LFOs by Case Type in SMC, 2000-2017 ( $\mathrm{N}=40,672)$. \\
\hline Table 3. & Percent Incarcerated after \$175 LFO sentence. \\
\hline Figure 1. & $\begin{array}{l}\text { Number of cases with LFOs in Seattle Municipal Court, and cases with LFOs } \\
\text { per } 1,000 \text { persons by violation type: } 2000-2017 \text {. }\end{array}$ \\
\hline Figure 2. & $\begin{array}{l}\text { Cases with LFOs in Seattle Municipal Court per 1,000 population by } \\
\text { race/ethnicity, } 2017 \text {. }\end{array}$ \\
\hline Figure 3. & $\begin{array}{l}\text { Median case-level LFO debt originally ordered, after court adjustment, and paid } \\
\text { by case type by race/ethnicity, } 2015-2017 \text {. }\end{array}$ \\
\hline Figure 4. & $\begin{array}{l}\text { SMC LFO debt originally ordered, after court adjustment, and paid by case } \\
\text { type, } 2017 \text {. }\end{array}$ \\
\hline Figure 5. & $\begin{array}{l}\text { Average amount ordered, amount ordered after adjustment by court, and } \\
\text { amount paid by kind of LFO and by case type: Criminal. }\end{array}$ \\
\hline Figure 6. & $\begin{array}{l}\text { Average amount ordered, amount ordered after adjustment by court, and } \\
\text { amount paid by kind of LFO and by case type: Infractions. }\end{array}$ \\
\hline Figure 7. & $\begin{array}{l}\text { Age of LFO accounts at closing date by case type in Seattle Municipal Court, } \\
2007-2017 \text {. }\end{array}$ \\
\hline Figure 8. & Expected length of LFO account time to close by case type, $2007-2017$. \\
\hline Figure 9. & $\begin{array}{l}\text { Proportion sentenced to incarceration in Washington Superior Courts after } \\
\text { being sentenced to } \$ 175 \text { in SMC LFOs (adjusted) by race, case type, and } \\
\text { payment / non-payment, logistic regression expected values. }\end{array}$ \\
\hline Figure 10. & $\begin{array}{l}\text { Proportion charged with driving with a suspended license (3) after being } \\
\text { charged with an SMC LFO, logistic regression expected values. }\end{array}$ \\
\hline Figure 11. & $\begin{array}{l}\text { Adjusted SMC LFO debt per 1,000 residents by race/ethnicity and case type, } \\
2017 \text {. }\end{array}$ \\
\hline
\end{tabular}


An Analysis of Court Imposed Monetary Sanctions in Seattle Municipal Courts

\begin{tabular}{|l|l|}
\hline Figure 12. & $\begin{array}{l}\text { Ratio of adjusted SMC LFO debt per 1,000 residents by race/ethnicity relative } \\
\text { to white, 2017. Dashed line indicates equality. }\end{array}$ \\
\hline Figure 13. & $\begin{array}{l}\text { LFO debt ordered (adjusted) per 1,000 residents in Washington Municipal } \\
\text { Courts, by population size of city. }\end{array}$ \\
\hline Figure 14. & $\begin{array}{l}\text { LFO cases per 1,000 persons by case type and size of city population in } \\
\text { Washington Municipal Courts, 2014. }\end{array}$ \\
\hline Figure 15. & $\begin{array}{l}\text { Median LFO ordered (adjusted) in Washington Municipal Courts by population } \\
\text { size of city, 2014. }\end{array}$ \\
\hline
\end{tabular}




\section{Introduction}

While the laws, policies and court practices vary, each state in the United States imposes some sort of scheme to sentence law violators to justice system fees, fines related to specific offenses, and restitution to directly or indirectly reimburse victims, in addition to a host of costs related to non-full payment. Many states have legislatively established "mandatory" fines or fees, where judges have no discretion in whether or not to sentence people, even those deemed indigent. ${ }^{i}$ Over the past twelve years, research has emerged to outline local and state level practices, documenting the varying dimensions of court mechanisms used to assess the costs, monitor repayment and non-payment, and punish people who do not pay. ${ }^{\text {ii }}$ This research has examined the consequences of court imposed fines and fees on the lives and families of people who owe the debt, the practices by which local jurisdictions collect the penalties, and the disparate effects of monetary sanctions for youth, communities of color and people who are poor. ${ }^{\text {iii }}$ Research has also begun to give attention to justice practices related to the imposition of fines and fees, such as the privatization of services and products within justice systems and state revenue generation foci and practices. ${ }^{\text {iv }}$

In this report, we use an expansive definition of legal financial obligations (LFO), which is inclusive of all financial debts imposed by a court because of a criminal charge or infraction. We use the term LFO interchangeably with the term of monetary sanctions. The definition we use is broader than typical definitions that narrowly focus on criminal cases only. However, in the eyes of debtors, debt arising from both traffic and non-traffic infractions can have similar consequences as can debt arising from criminal cases. Our goal in this report is to capture the total impacts of the broad system of monetary sanctions in Seattle. While our analysis focuses on data from the Seattle Municipal Court, this system depends on the actions wide range of institutions, including the court itself, the Seattle Police Department, the City Attorney's Office, and others. As such, our results and interpretations may differ from those that use more narrow criteria to define legal financial obligations. Our analyses treat LFOs as inclusive of all monetary sanctions that individuals may incur because of cases processed in Seattle Municipal Court.

Legal Financial Obligations, as defined in Washington State statute include the fines, fees, costs imposed by the court as the result of a criminal convictions. Washington State's Legal Financial Obligations are mandated by RCW 9.94A.760. ${ }^{\vee}$ Specific fines and fees are embedded throughout the RCW. The mandatory LFOs include: a Victim Penalty Assessment (VPA) which imposes $\$ 500$ for each felony or gross misdemeanor conviction and a $\$ 250$ fee for each misdemeanor conviction (RCW 7.68.035). The DNA Collection Fee imposes a one-time fee of $\$ 100$ for a crime specified in RCW 43.43 .754 and must be sentenced (this is not mandatory for persons with mental health conditions). Furthermore, restitution shall be ordered when a person is convicted of a felony offense resulting in injury, damage or loss of property. Some LFOs are crime specific fines and are mandatory based on type of offense (e.g., sex offense). Other fees and costs such as, criminal filing fee, conviction fee or jury fee shall not be imposed if a person is deemed indigent or has a mental health condition.

We have been asked by the Seattle Office for Civil Rights to conduct an analysis of the sentencing and collection of fines and fees by the Seattle Municipal Court (SMC). It is 
important to note that as national, as well as Washington specific research, has shown, the sentencing and citation of fines and fees is just one discretionary point within the overall system of monetary sanctions. This punishment schema entails several discretion points, including, citations by police officers, sentencing by court officers, management of debt by court clerks and private collection agencies, judicial and probationary supervision and punishment of people who owe court debt. As our analyses illustrate, many of the cases that come before the SMC have been initiated not by Seattle Municipal Court judges, but instead via traffic violations issued by Seattle police and parking enforcement officers. As such, our concluding discussion of policy implications suggests a broad range of officials, including the Seattle Police Department and SMC, to collectively think broadly about this system of monetary sanctions and how best to alleviate the consequences for people who are unable to pay the debt and who are processed through multiple discretion points that lead to a cumulative negative effect.

\section{Report Aims}

The aim of this report is to outline four dimensions related to the citation, sentencing and management of fines and fees by the Seattle Municipal Court. We aim to better understand the type of SMC cases associated with LFO sentences and the time it takes for people to pay off the debt. We are also interested in how the debt might matter for subsequent criminal court involvement. Might carrying LFO debt increase individuals' contact with superior courts in Washington State? Furthermore, a key outstanding question about LFOs is the extent to which there may be racial and ethnic differences in citations, sentencing, ability to pay the debt and subsequent court contact. Also, of interest is how the City of Seattle Municipal Court's LFO sentencing, and the duration of debt and ability of citizens to pay that debt back, compares to other cities in Washington State. From this set of questions, we have arrived at the following dimensions for analysis: ${ }^{\mathrm{vi}}$

1. Extent and characteristics of unpaid debt

2. Impact of SMC fines and fees on people who cannot afford them

3. Exploration of racial disparities in traffic and non-traffic infractions

4. Comparison of the City of Seattle LFO process with other cities in WA State

\section{Summary of Key Findings:}

In what follows we provide a detailed analysis of the scope of fines and fees sentenced and collected by Seattle Municipal Court through 2000-2017. In sum, we present the following key findings from our data analysis:

1. There has been a remarkable decline in cases filed in Seattle Municipal Courts between 2000 - 2017, even as the population size of Seattle increased during this time period.

2. People sentenced to criminal traffic cases tended to have their LFO accounts open (not fully paid) for longer periods of time relative to other types of traffic cases. 
3. For each class of case, Black men and women are significantly more likely than their peers to be sentenced to incarceration through a Washington superior court following a paid Seattle Municipal Court legal financial obligation sentence (SMC LFO).

4. Black men and women are more likely to be incarcerated following an unpaid SMC LFO than are any other racial or ethnic group.

5. People of color have a higher likelihood than White people to be charged with a DWLS3 following a Seattle Municipal Court legal financial obligation sentence. This is especially pronounced for Black Seattle drivers. 


\section{Data and Methods}

All cited or convicted cases from 2000-2017 were provided by the Seattle Municipal Court via the JIS (District and Municipal Court Judicial Information System). ${ }^{\text {vii }}$ This data system assists court officers and clerks in managing and reporting Washington State's district and municipal court cases. All analyses were conducted by Frank Edwards, using the R statistical programming language. Comparisons to other jurisdictions use data from the Washington Administrative Office of the Courts (AOC) on LFO sentencing in all other Washington Municipal Courts between 2000 and 2014.

Note that the analyses below exclude a very small number of cases in which total assessed LFOs equaled over one million dollars. The analyses also exclude a small number of felony cases recorded in the data. Population data are obtained from the 2000 and 2010 census, and intervening years are imputed through linear interpolation.

While each case can be assessed multiple LFOs (mean LFOs per case with assessed LFOs in sample $=6.6$ ), all reported LFO figures are aggregated to the case-level to ensure comparability across categories of violations and between SMC and other courts of limited jurisdiction. We compute three values to describe the legal financial obligations assessed for each case: initial amount ordered, amount owed after court adjustment, and amount paid.

Table 1. Median annual total SMC LFOs by case type (in 2018 inflation adjusted dollars)

\begin{tabular}{|l|l|l|c|c|c|}
\hline Case type & $\begin{array}{l}\text { Originally } \\
\text { ordered }\end{array}$ & $\begin{array}{l}\text { After court } \\
\text { adjustment }\end{array}$ & $\begin{array}{l}\text { \% Adjusted } \\
\text { from Original }\end{array}$ & Paid & $\begin{array}{l}\% \text { Paid from } \\
\text { Adjusted }\end{array}$ \\
\hline $\begin{array}{l}\text { Infraction } \\
\text { Traffic }\end{array}$ & $\$ 24,467,354$ & $\$ 9,471,204$ & $39 \%$ & $\$ 8,080,052$ & $85 \%$ \\
\hline $\begin{array}{l}\text { Infraction Non- } \\
\text { Traffic }\end{array}$ & $\$ 824,678$ & $\$ 406,969$ & $49 \%$ & $\$ 283,779$ & $70 \%$ \\
\hline Criminal Traffic & $\$ 3,598,035$ & $\$ 579,825$ & $16 \%$ & $\$ 528,681$ & $91 \%$ \\
\hline $\begin{array}{l}\text { Criminal } \\
\text { Traffic: DUI }\end{array}$ & $\$ 4,033,011$ & $\$ 642,556$ & $16 \%$ & $\$ 543,827$ & $85 \%$ \\
\hline $\begin{array}{l}\text { Criminal Non- } \\
\text { Traffic }\end{array}$ & $\$ 12,041,164$ & $\$ 356,704$ & $3 \%$ & $\$ 304,264$ & $85 \%$ \\
\hline
\end{tabular}

The initial amount ordered is a simple sum of all ordered LFOs at the case-level prior to any adjustment by the court. The amount paid is a sum of the total amount paid on LFOs at the caselevel. The amount owed after court adjustment is computed according to the following rules: 
- If the current amount due on an account is recorded as zero dollars, the adjusted amount is equal to the paid amount

- If the current amount due on an account is greater than zero dollars, the adjusted amount is equal to the current amount owed plus the total paid.

Each of these values is inflation adjusted to January 2018 dollars using the consumer price index to ensure comparability over time.

\section{Race, Ethnicity and Surname Analysis}

SMC does not collect race/ethnicity for subject to LFOs. Instead, it relies on and reports data collected by police, and these data do not report Latinx ethnicity. To disaggregate Latinx people from non-Hispanic white people, and to recover information on some cases where race/ethnicity data is missing (about 10 percent of cases), we construct a two-stage imputation process based on a method developed by Imai and Khana ${ }^{\text {viii }}$. First we match surnames to Census records that provide estimates of the share of the population with a given surname. Then, we use data on the racial composition of the population in King County, in combination with matched name probabilities, to impute the race/ethnicity of court records missing this demographic information. We classify all records with an imputed posterior probability of Hispanic ethnicity greater than 0.75 (conditional on surname and population composition) as Hispanic, and all those less than or equal to a posterior probability of Hispanic ethnicity to be non-Hispanic. We use a similar procedure for missing data in the AOC records for other Washington courts. Prior to imputation, about 10 percent of cases were missing data on race/ethnicity. After imputation, about 8 percent of cases are missing data on race/ethnicity. Additionally, about 8 percent of cases recorded as white in the initial data are reclassified as Latinx.

\section{Incarceration History}

We establish an individual's incarceration history by linking individuals to AOC data on superior court sentences by individual surname and date of birth. This procedure results in about 700,000 individuals with records in both SMC and AOC data. From these matches, we then identify records where an individual was ever sentenced to jail or prison by any superior court in Washington, and identify those cases where SMC LFO sentences preceded a first incarceration sentenced from a superior court based on AOC sentencing dates and SMC filing dates.

\section{Case Types}

We use SMC provided case type codes, but distinguish DUI cases from other criminal traffic cases by recoding all cases with a finding of "committed" or "guilty" for any case with a violation code listed as SMC 11.56.020, "Persons under the influence of intoxicating liquor, marijuana, or any other drug." These DUI cases are recoded as a separate category, and are excluded from the criminal traffic case type. 


\section{Findings}

\section{Extent and characteristics of paid and unpaid debt}

Our first step to examine legal financial obligations (LFOs) from Seattle Municipal Court (SMC) is to assess the volume of cases, the volume of debt sentenced, and the volume of debt that remains uncollected and under the city's purview. Figure 1 shows the total volume of cases with ordered LFOs in SMC between 2000 and 2017. The top panel of Figure1 adjusts the total caseload with ordered LFOs to a rate per 1,000 Seattle residents, and the bottom panel displays the caseload as an unadjusted count.

Figure 1. Number of cases with LFOs in Seattle Municipal Court, and cases with LFOs per 1,000 persons by violation type: $2000-2017$.

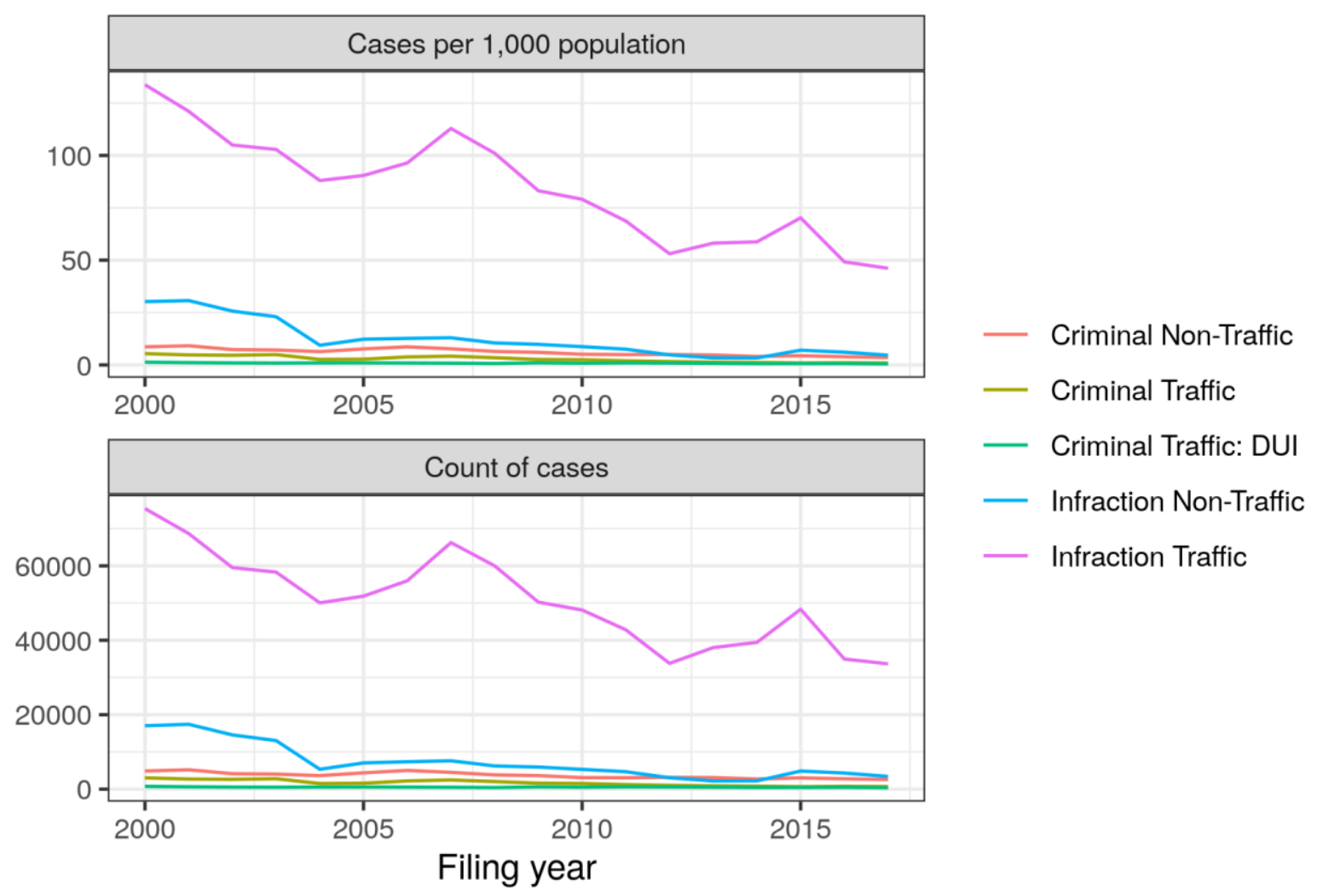

Cases have trended downward over this 18-year period. In 2000, SMC handled over 100,000 total cases, and the caseload total was at a minimum in 2017 at about 40,000 cases with ordered LFOs. Because Seattle's population grew substantially over this time period, the per capita rate of LFO orders declined even more rapidly, from a peak of about 200 cases with LFOs per 1,000 residents in 2000 to a minimum of about 50 cases with LFOs per 1,000 residents in 2017, about 25 percent of the rate of LFO debt orders per capita in 2000. Note that across this time period, the overwhelming majority of SMC cases with LFOs were traffic infractions. Non-traffic infractions and criminal cases made up a minority of the remaining cases. In 2017, SMC ordered LFOs in 40,672 cases. Table 2. Illustrates that of these cases, 83 percent were traffic infractions, 
8 percent were non-traffic infractions, 6 percent were non-traffic criminal cases, 2 percent were criminal traffic cases, and 1 percent were DUI cases.

Table 2. Distribution of LFOs by Case Type in SMC, 2000-2017 $(\mathrm{N}=40,672)$.

\begin{tabular}{|l|c|}
\hline \multicolumn{1}{|c|}{ Case Type } & \% of Total Cases \\
\hline Traffic Infractions & $83 \%$ \\
\hline Non-Traffic Infractions & $8 \%$ \\
\hline Non-Traffic Criminal & $6 \%$ \\
\hline Criminal Traffic & $2 \%$ \\
\hline DUI & $1 \%$ \\
\hline
\end{tabular}

Figure 2 displays the distribution of the SMC LFO caseload across Seattle's population by race/ethnicity using data from cases filed in 2017. Each panel of the figure represents a class of cases. Note the variation in the scale of the y-axis for case rates across categories. For all classes of cases, people of color are ordered LFO debt more frequently than White people in Seattle. In 2017 Black drivers in Seattle were issued 2.6 times more traffic infractions with LFOs per capita than were White drivers. Latinx drivers were issued 1.7 times more traffic infractions than White drivers. American Indians / Alaska Natives were issued LFOs for criminal non-traffic offenses at a per capita rate 6.7 times higher than the rate for white Seattle residents. Non-traffic infraction LFOs were ordered 3.7 times more frequently for American Indians/Alaska Natives than for Whites, and Black Seattlites were issued LFOs for non-traffic infractions at a rate 3.1 times higher than Whites. These disparities are largely a function of case volume, driven by law enforcement activity and population differences. 
Figure 2. Cases with LFOs in Seattle Municipal Court per 1,000 population by race/ethnicity, 2017
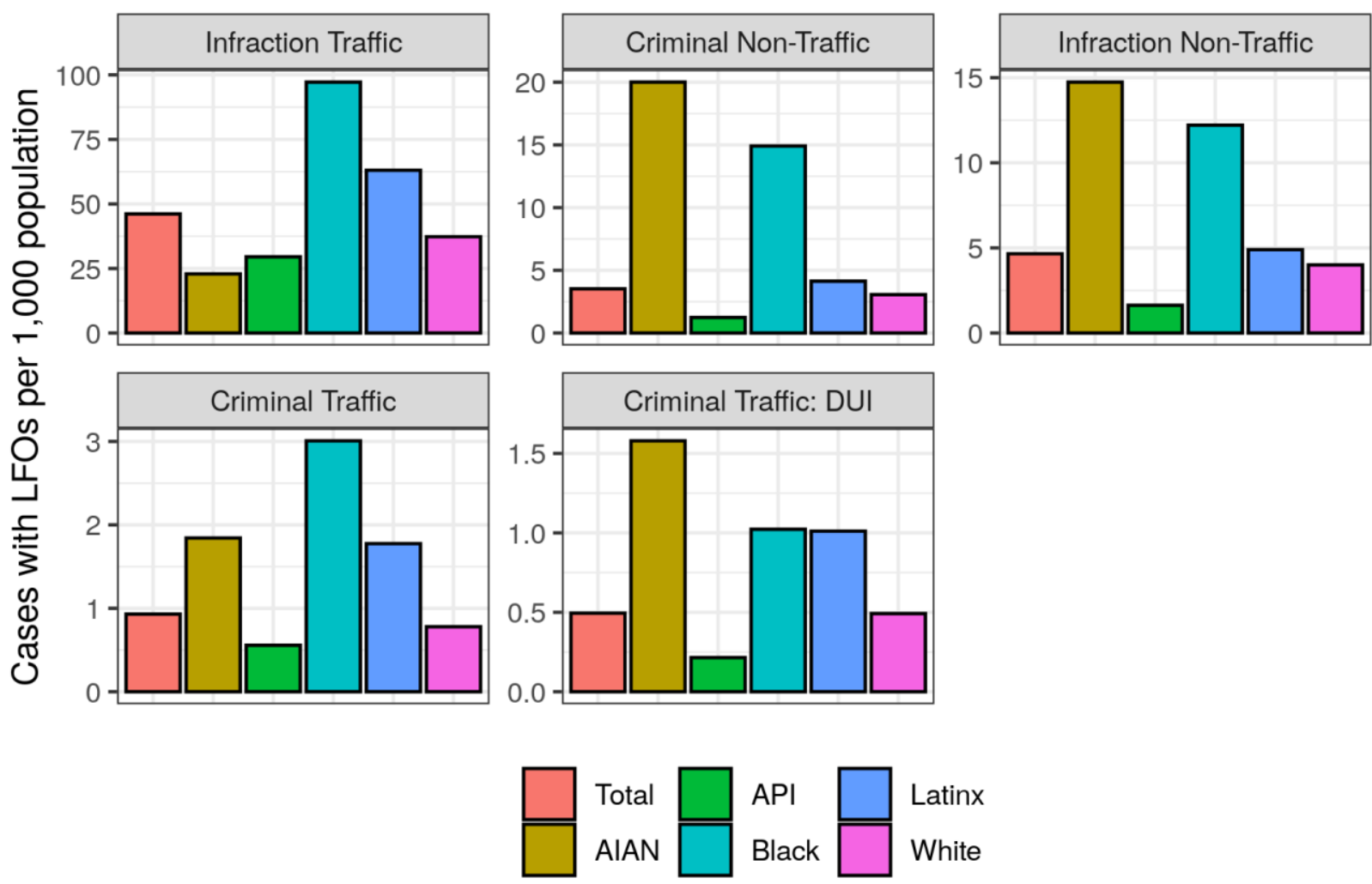

As shown in Figure 3, there are few differences across racial and ethnic groups in initial SMC debt orders and in final amounts ordered after court adjustment for the most common categories of cases. There is more heterogeneity in non-DUI criminal offenses in initial orders, but these offenses are relatively rare in SMC and heterogeneous in composition. Despite some apparent inequalities in high initial sentences for criminal traffic and non-traffic cases, note that after court adjustment, many criminal cases have their balances reduced to near-zero, and initial inequalities are generally reduced or eliminated for criminal LFOs. For DUIs and infraction violations, racial and ethnic differences in median initial and adjusted sentences are minimal.

Coupled with the results in Figure 2, these findings strongly suggest that SMC sentencing practices themselves are not a key driver of racial inequalities in Seattle LFO debt. Instead, the flow of cases into the court appears to be the key driver of population-level inequalities. As explained in the introduction, LFOs are situated within a system of monetary sanctions whereby many are triggered with the citation of tickets by law and parking enforcement. While other LFOs are sentenced directly by court judges. It appears that much of the disproportionate burden of LFOs for people of color managed by SMC stems from the issuing of traffic citations by police and traffic enforcement. When these cases come into the SMC, as with other initial LFO sentences, much of the disparity in sentence amounts are adjusted by SMC court officials. 
Figure 3. Median case-level LFO debt originally ordered, after court adjustment, and paid by case type by race/ethnicity, 2015 - 2017

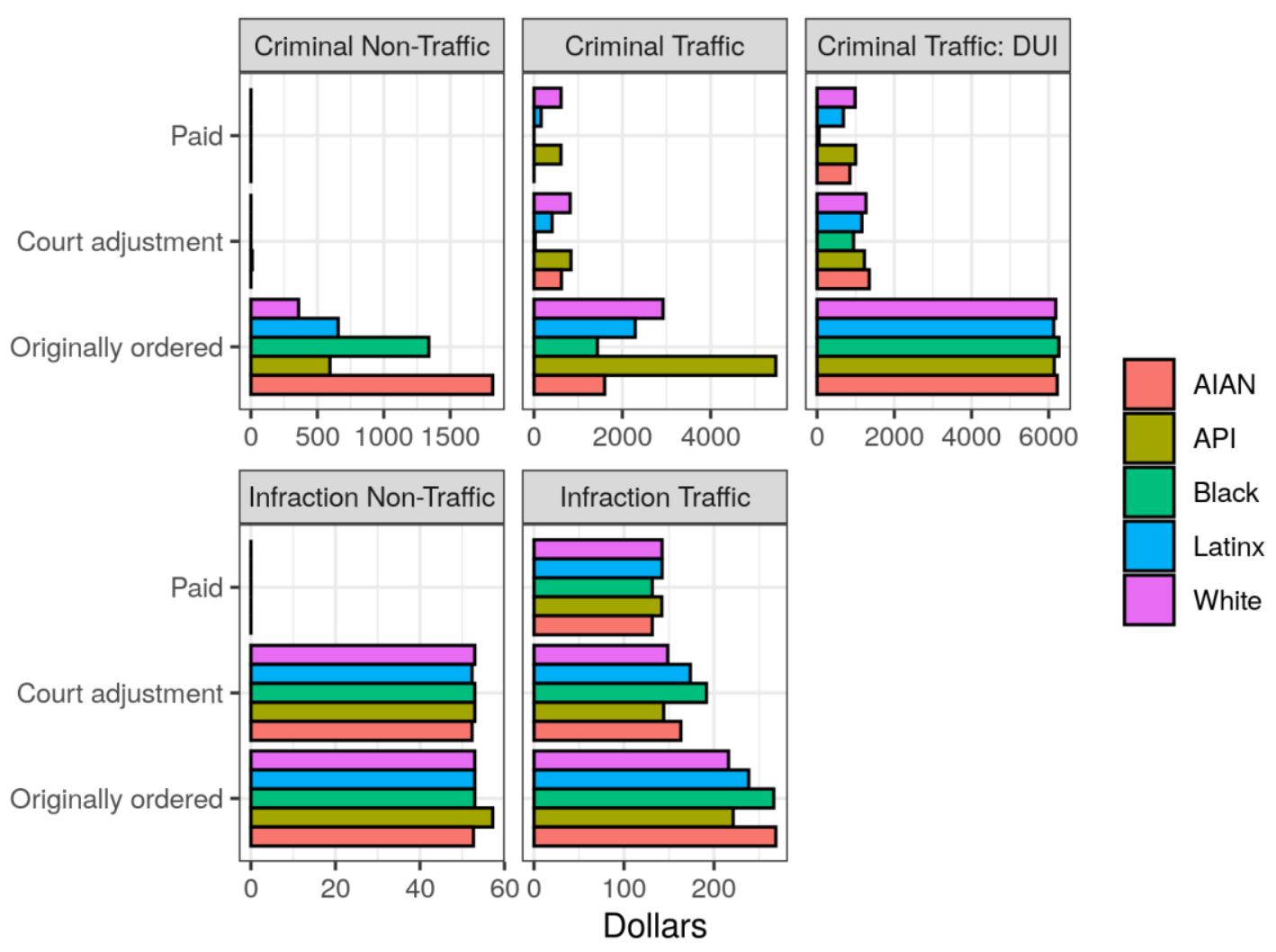

Figure 4 shows how initial orders relate to actual amounts due after court adjustment, and how much of this adjusted balance remained outstanding for accounts filed in 2017. The majority of the initially ordered debt through SMC was for traffic infractions. In 2017, over 10 million dollars of LFOs were ordered through SMC for traffic infractions. After court adjustment, the balance was reduced to 7.2 million dollars, a reduction of about 35 percent from the initial amount ordered. Of this adjusted amount, about 4.8 million was paid before the end of the year in 2017, about 66 percent of the adjusted balance, leaving about 34 percent of the adjusted traffic infraction LFO orders outstanding within this single year of orders. Criminal non-traffic offenses had the second highest total initial LFO amount ordered, at about 5.5 million dollars.

However, the court dramatically reduced this balance due, to an aggregate of about 360 thousand dollars, a reduction of about 93 percent of the initial amount ordered. Of this much reduced balance, most was paid; only about 20 percent of the criminal non-traffic LFO balance was unpaid by the end of 2017. We see similar patterns for criminal traffic (DUI and non-DUI) offenses, with aggregated initial orders of over 2 million reduced by the court to about 400 thousand, a reduction of about 80 percent. For both DUI and other criminal traffic offenses, the majority of the remaining balance was paid within the year. Traffic infractions represent a smaller share of the total debt issued by the court, about 650 thousand in initial orders, and 400 thousand after court adjustment. This reduction is of a similar magnitude to the reductions ordered by the court for traffic infractions, about a 39 percent decrease from initial orders. Of this remainder, much remained unpaid, about 60 percent. 
Figure 4. SMC LFO debt originally ordered, after court adjustment, and paid by case type, 2017

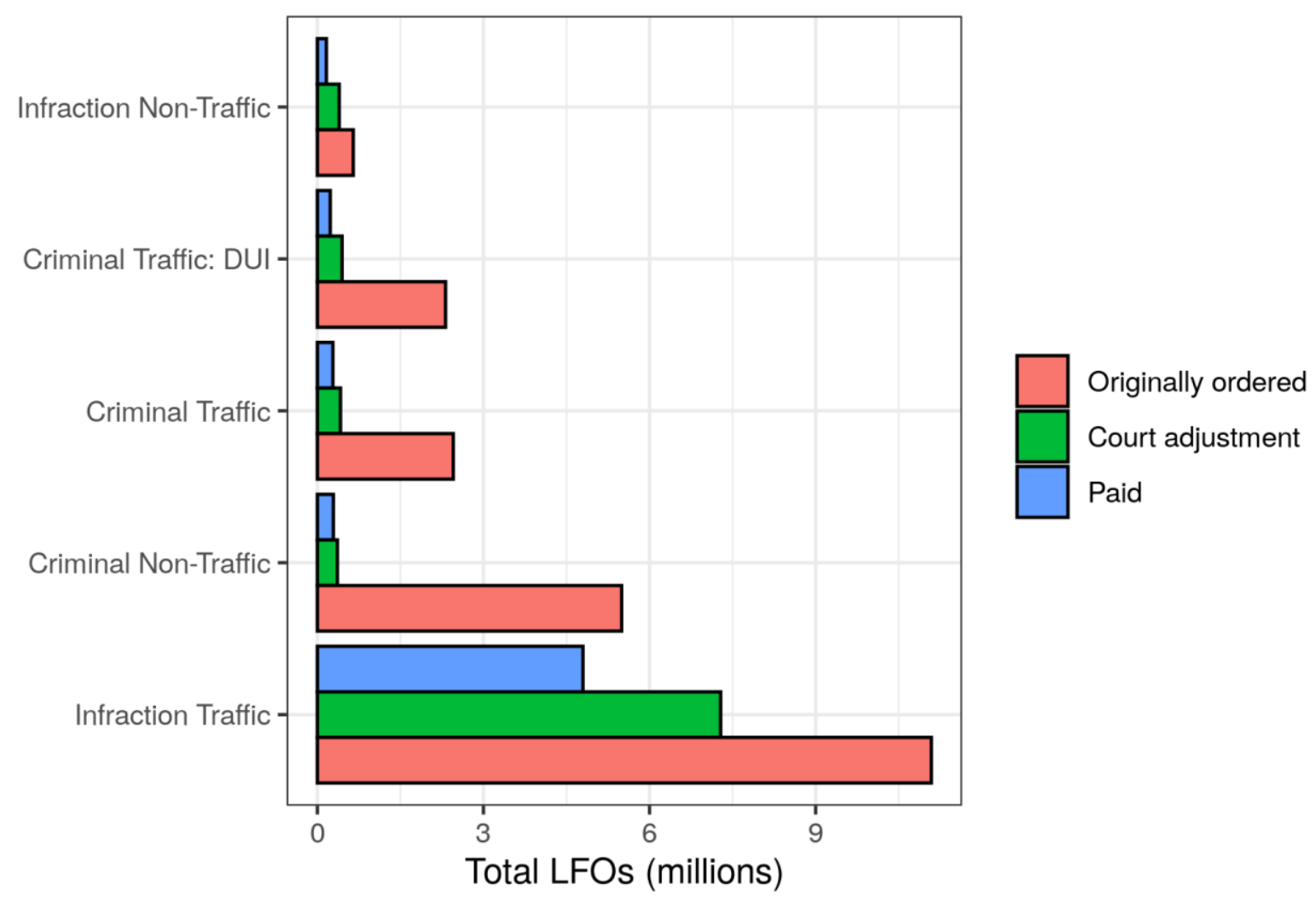

Figure 5 examines how the court adjusted commonly imposed individual legal financial obligations in typical non-DUI criminal cases in 2017. For non-traffic criminal offenses, the average initial fine was about $\$ 4900$. However, after court adjustment, the average balance due for fines in criminal non-traffic cases was about $\$ 10$, a dramatic reduction. Other fees and assessments were typically also reduced by large amounts. Restitution, on the other hand, was typically not dramatically reduced by the court. On average across all cases, the ordered restitution amount was ordered about $\$ 170$, and the average amount after adjustment was about $\$ 130$. Similar patterns hold for criminal traffic cases. Fines were reduced (on average) by about 90 percent and made up the overwhelming majority of initial LFO orders. Other classes of LFOs were not reduced by the same magnitude, but initial orders were typically quite low.

Figure 6 displays routinely imposed LFOs for both traffic and non-traffic infractions. Note that there are many more types of commonly issued LFOs in these cases than in criminal cases in SMC. Penalties and fines make up the bulk of non-traffic infraction LFO orders, at around \$100 each in initial penalties and fines. The court often reduces the penalty order substantially, but infrequently reduces ordered fines in these cases. For both traffic and non-traffic infractions, a battery of fees, surcharges, and assessments are imposed on cases. For example, the most commonly imposed charges include a time payment setup fee, a criminal conviction fee, a trauma care system surcharge, an auto theft prevention assessment, a JIS fee, a default penalty, an accident penalty, a cancellation fee and a deferred finding administrative fee. While each of 
these charges is typically a small amount, they are rarely reduced and may add up to substantial total balances.

Figure 5. Average amount ordered, amount ordered after adjustment by court, and amount paid by kind of LFO and by case type: Criminal

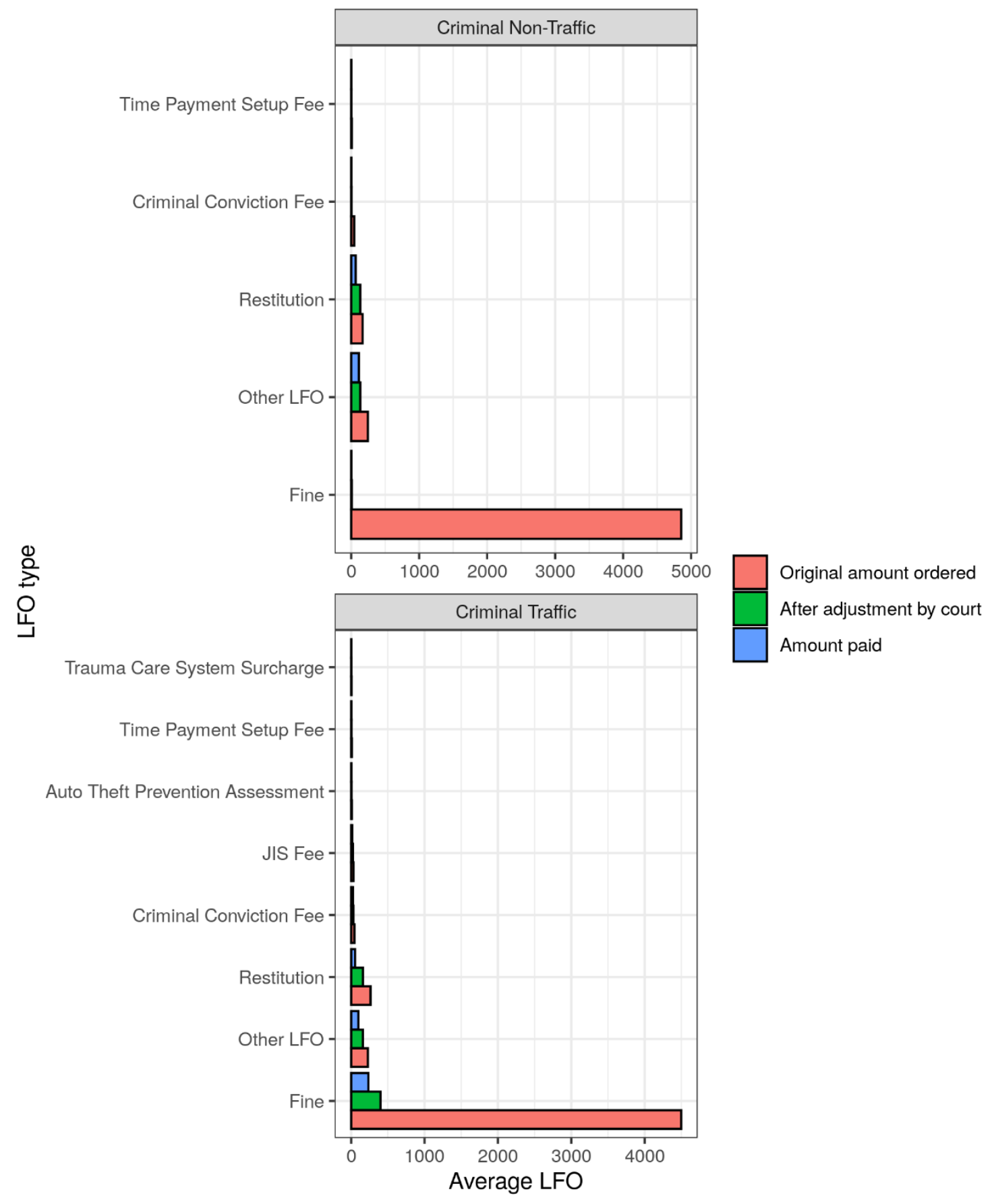


Figure 6. Average amount ordered, amount ordered after adjustment by court, and amount paid by kind of LFO and by case type: Infractions

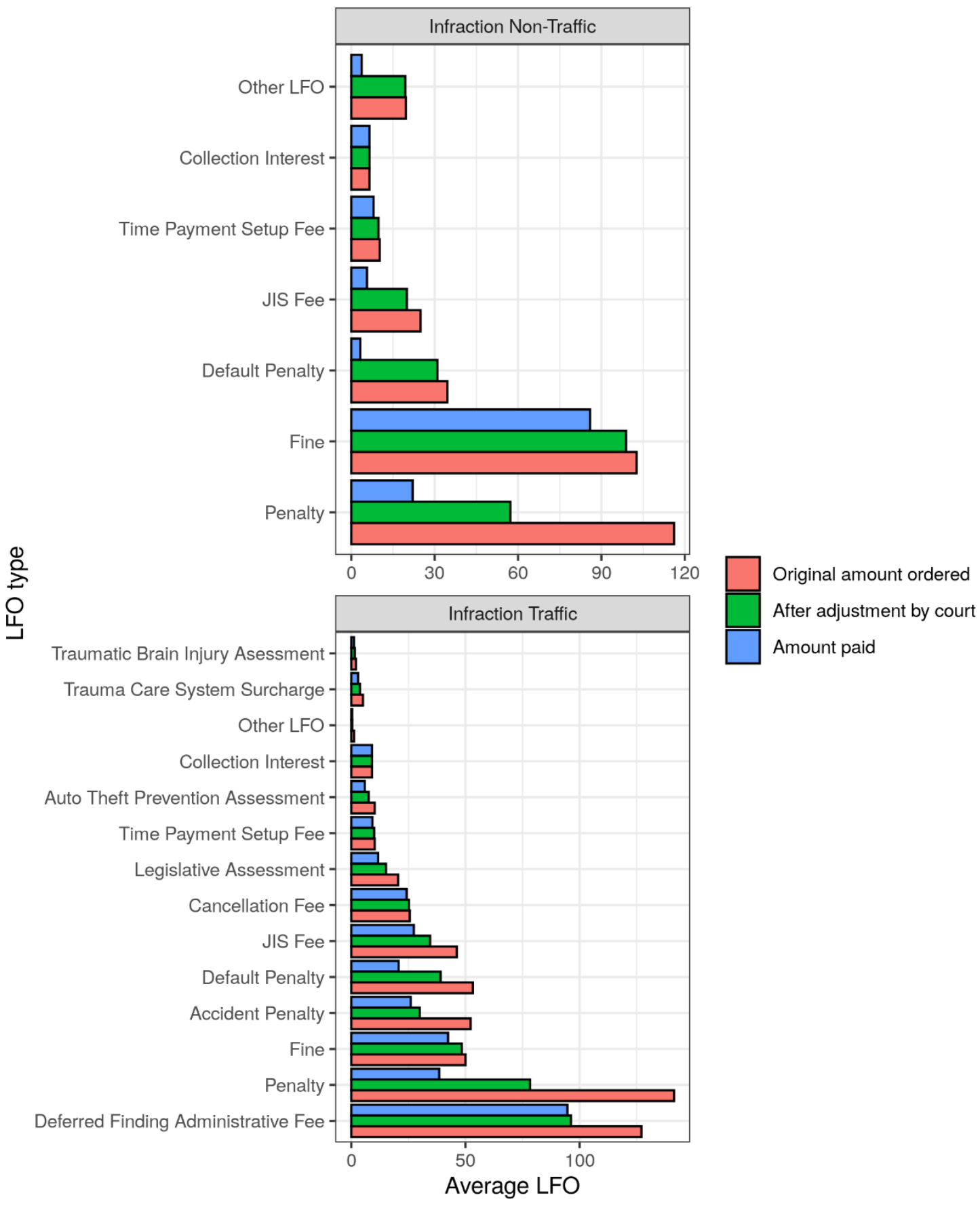


Figure 7 shows the average age of LFO accounts in SMC by case type for cases filed between 2007 and 2017, setting a maximum age of 10 years. Note the very short age for most infraction accounts. The average traffic infraction account is opened and closed within 4.3 months. The average non-traffic infraction account is opened and closed with 6.2 months. Criminal accounts tend to be sentenced to much higher amounts (see Figure 3), and tend to remain open much longer. The average non-traffic criminal account remains open for 1.2 years, but note the long tails on the distribution of case ages; some accounts remain open much longer. The average criminal traffic account remains open for about 2 years, and the average DUI account remains open for about 4.6 years. Note that a non-trivial number of criminal accounts remained open and not fully paid for a full 10 years.

Figure 7. Age of LFO accounts at closing date by case type in Seattle Municipal Court, 2007 2017

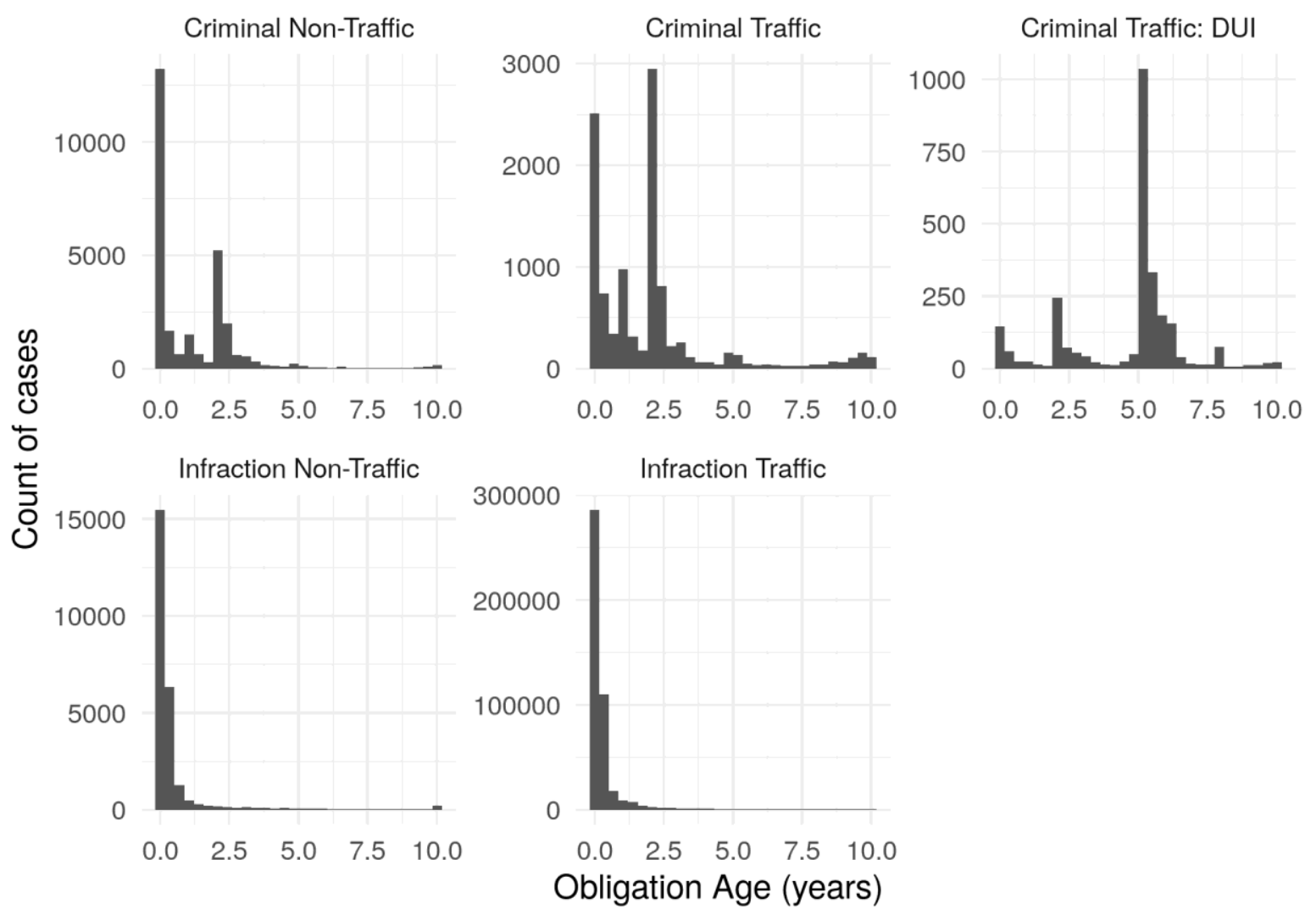


Figure 8. Expected length of LFO account time to close by case type, 2007 - 2017

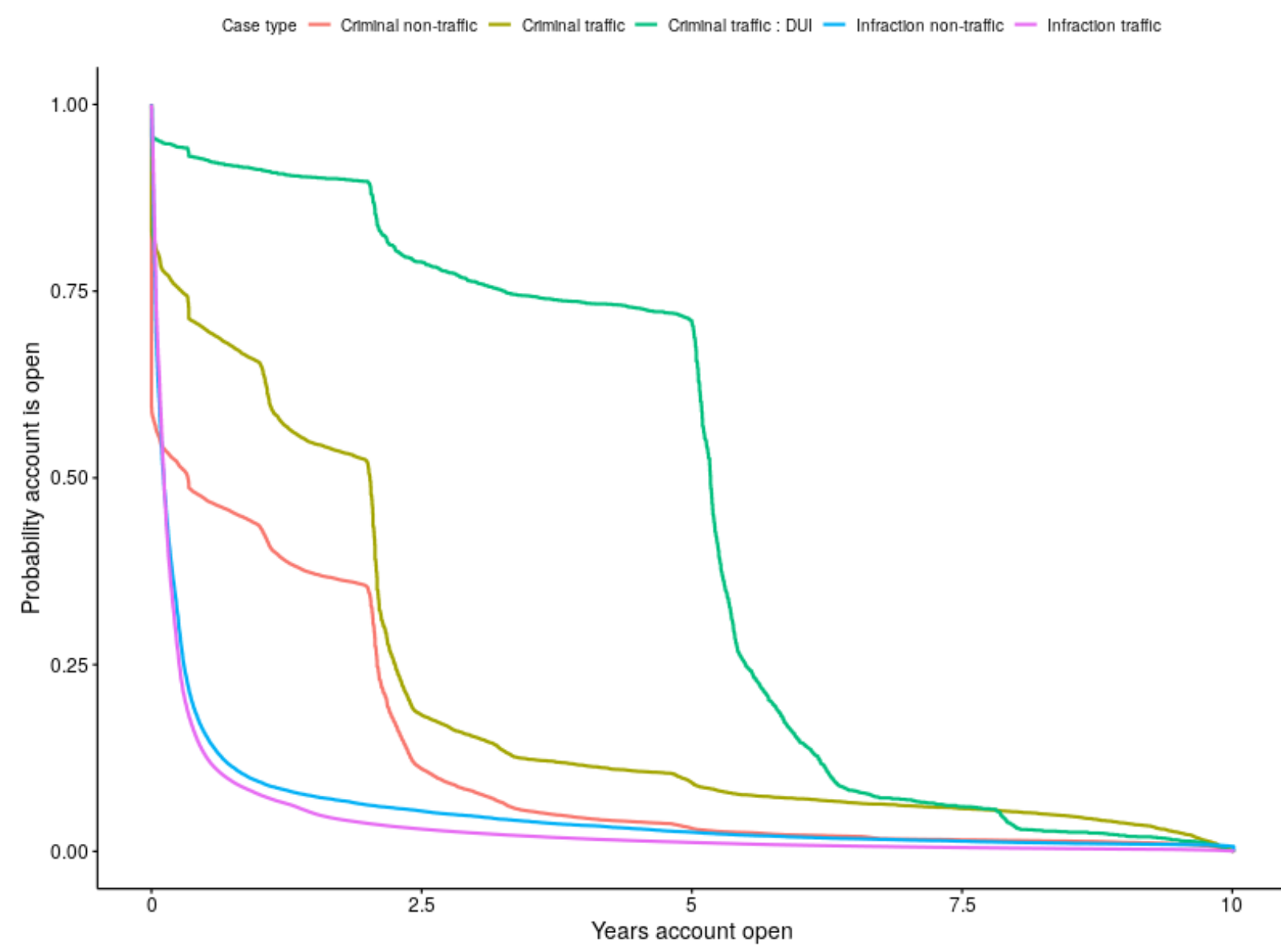

Figure 8 shows the results of a survival analysis of LFO account closure. Survival analysis is a statistical method that allows estimates the time to an event across different kinds of cases, including for cases that have not yet experienced the event (censoring). In this case, we estimate how long, on average, different kinds of LFO accounts remain open by building a statistical model that estimates the average time it takes until a case is closed. Below we illustrate the probability of an account remaining open as a function of the account's age and the case type. DUI cases tend to survive the longest. Over this period, about 75 percent of DUI LFO accounts are expected to remain open and not fully paid after five years. Other kinds of accounts tend to close much more quickly. Few infraction LFO accounts remain open after one year, and the majority of non-DUI criminal cases are closed within 2.5 years. Non-traffic criminal cases tend to close more quickly than criminal traffic cases. 


\section{Relationships between SMC LFOs and more serious criminal justice system contact}

In this section we are interested in understanding the criminal justice consequences for people who have unpaid court debt. We examine the relationship between court debt sentenced in SMC with a subsequent conviction in Washington State Superior court. We conduct a longitudinal analysis that explores whether court debt predicts future incarceration. That is, what is the likelihood that someone will be incarcerated if they carry LFO debt. Note that these are not causal estimates, and do not identify the effect of SMC fines and fees on future incarceration. Instead, our estimates describe associations between debt and future incarceration outcomes. The figures below should be interpreted as the expected conditional probability of future incarceration after SMC LFOs for each group. However, these estimates do not capture the independent impact of SMC LFOs on future incarceration because unmeasured variables likely confound the relationship between court debt and future criminal justice outcomes. However, these models can accurately predict the proportion of people in each category (e.g. White, with unpaid LFO) who are likely to experience a particular outcome after receiving an LFO through SMC.

In these models, we use data from the Washington Administrative Office of the Courts (AOC) to identify the first time a person was sentenced to jail or prison by a Washington Superior Court. We then match these first-time incarceration records to SMC LFO records based on a person's name and date of birth. Note that because some names or dates of birth likely do not exactly match across AOC and SMC data, these probabilities / proportions should be taken as conservative estimates. Also, note that these models predict first incarceration sentenced in Superior Court in Washington. It is possible that LFO sentencing relates to pre-trial incarceration or incarceration sentenced in municipal or district courts, to incarceration for technical violations of conditions of release or deferred adjudication, or for recidivism and desistance. These models do not capture these outcomes.

Figure 9 displays the results of a logistic regression model of the probability of being sentenced to jail or prison in a Washington Superior court following sentencing to LFO debt in SMC. We display predicted probabilities of incarceration from a regression model that assumes the LFO was sentenced in 2010, that the amount sentenced was $\$ 175$, and that the person had not been previously been sentenced to incarceration in a Washington Superior Court. We estimate these probabilities separately for men and women, and by race/ethnicity. Note that model inputs include defendant race, gender, case type, total obligations sentenced, whether any payment was recorded, and the year in which the case was filed.

We begin by examining the likelihood of a person receiving a sentence to jail or prison by a Washington State Superior Court judge among the population of people who have been sentenced to SMC LFOs and who have paid them. The bottom panel of Figure 8 shows the probability of being sentenced to incarceration by a superior court following LFO sentencing in SMC when the balance of the sentenced LFO was paid in full by race and sex. For each class of case, Black men and women are significantly more likely than their peers to be sentenced to incarceration following an SMC LFO paid in full. This includes non-criminal infractions. 
Figure 9. Proportion sentenced to incarceration in Washington Superior Courts after being sentenced to $\$ 175$ in SMC LFOs (adjusted) by race, case type, and payment / non-payment, logistic regression expected values.

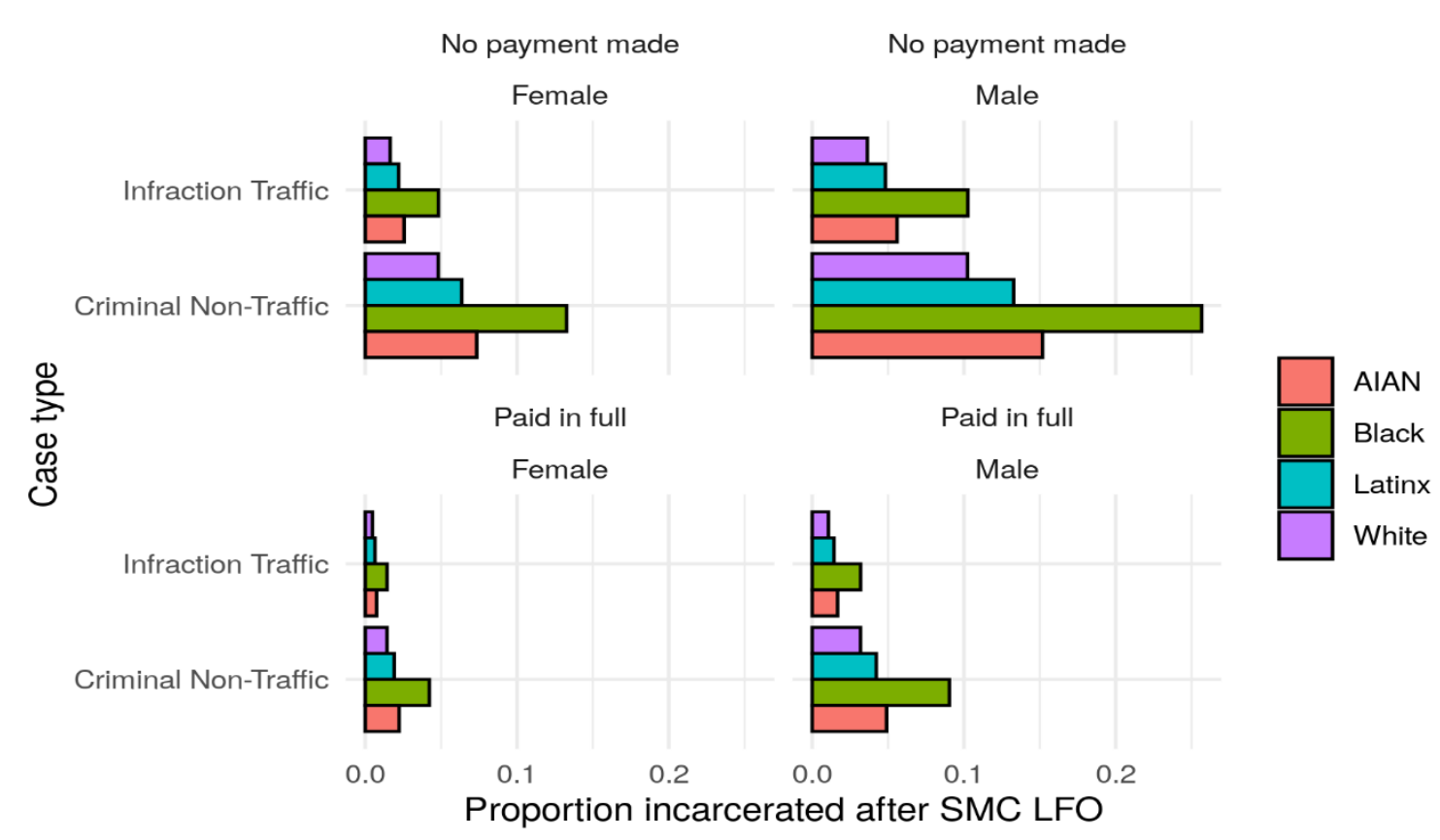

Table 3. Highlights these findings for Black and White men. We estimate that a Black man sentenced to a $\$ 175$ LFO in SMC for a traffic infraction that has paid their LFOs in full has about a 3 percent probability of being later sentenced to incarceration in a Washington Superior Court, compared to about a 1 percent probability for White men. For criminal non-traffic offenses, Black men have about a 9 percent chance of being incarcerated through a superior court following a paid SMC LFO, compared to a 3 percent chance for White men. We find that a Black man with an unpaid LFO from a criminal non-traffic SMC case will have a 26 percent probability of later incarceration through WA Superior courts. This compares to 10 percent probability for White men. In sum, Black men and women are more likely to be incarcerated following an unpaid SMC LFO than are any other group. American Indians / Alaska Natives are also more likely than White or Latinx people to be incarcerated following an SMC LFO. Our analysis finds a correlation between LFOs sentenced, paid and unpaid, for subsequent incarceration with key racial differences.

Table 3. Percent Likelihood of Subsequent Incarceration Post LFO \$175 sentence.

\begin{tabular}{|c|c|c|}
\hline & White Men & Black Men \\
\hline Traffic Infraction & & $3.2 \%$ \\
\hline Paid in full & $1.1 \%$ & $10.3 \%$ \\
\hline Unpaid & $3.6 \%$ & \\
\hline Criminal Non-Traffic & & $9.0 \%$ \\
\hline Paid in full & $3.2 \%$ & $25.7 \%$ \\
\hline Unpaid & $10.2 \%$ & \\
\hline
\end{tabular}




\section{Exploration of racial disparities in traffic and non-traffic infractions}

In this section we explore the extent to which there may be racial and ethnic differences in the issuance and sentencing of LFOs through SMC. We also explore how likely Seattle drivers are to receive a driving with a license suspended in the third degree (DWLS 3) ${ }^{\mathrm{ix}}$ charge after receiving any SMC LFOs, and whether there are any racial and ethnic differences in these probabilities. License suspension is a critical consequence of unpaid LFOs, and prior research suggests that low-income people of color may face a heightened risk of license suspension, leading them to more serious criminal justice system involvement (Harris 2016). In this way, license suspension resulting from unpaid LFOs may be an engine of racial and ethnic inequality.

Figure 10 shows the results of a logistic regression model estimating the probability that a driver will be charged with DWLS3 in SMC after receiving any LFO from SMC. Black drivers are far more likely than others to be charged with DWLS 3 following an SMC LFO. About 2.3 percent of all Black men who receive traffic infraction LFOs in SMC can expect to be charged with DWLS 3, compared to about 0.4 percent of White men. Latinx and American Indian / Alaska Native men charged with traffic infractions are more likely than White drivers to be charged with DWLS 3 following an SMC LFO; about 0.8 percent of Latinx men and 1 percent of AI/AN men, on average, will receive a DWLS3 charge in SMC following a traffic infraction at $2000-2017$ rates.

Figure 10. Proportion charged with driving with a suspended license (3) after being charged with an SMC LFO, logistic regression expected values

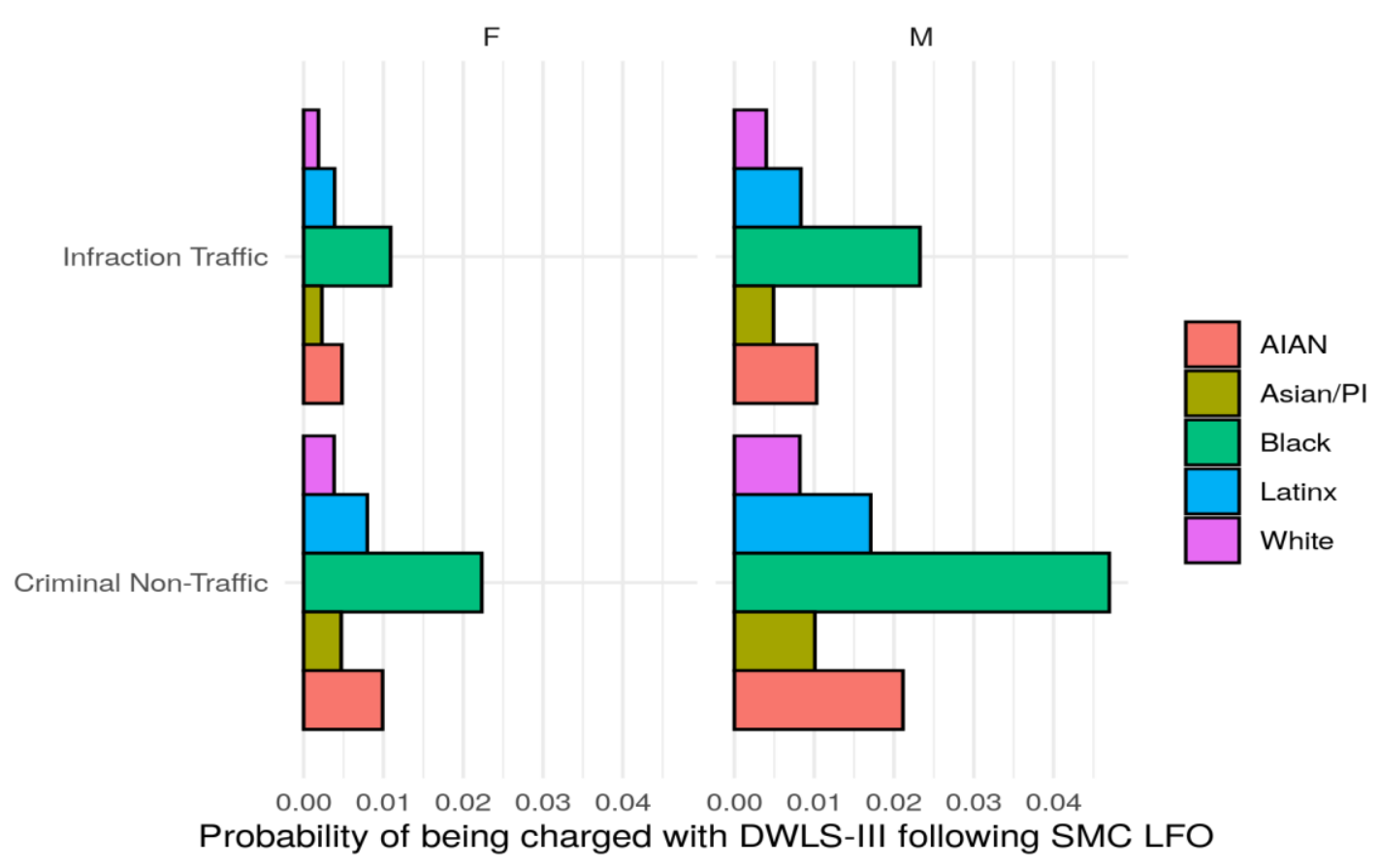


Figure 11. Adjusted SMC LFO debt per 1,000 residents by race/ethnicity and case type, 2017.

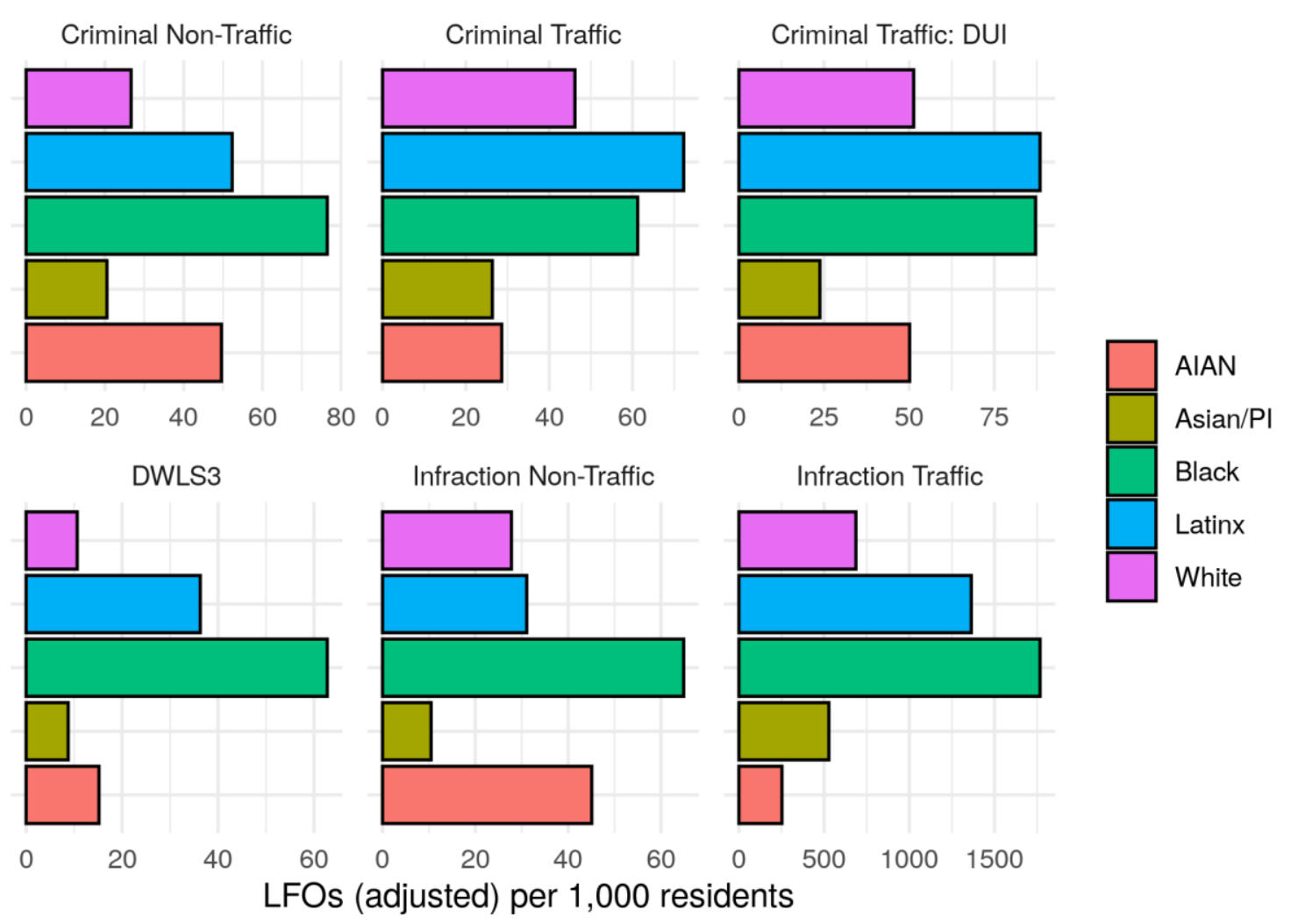

Next, we evaluate how LFO debt is distributed across groups in Seattle. Figure 11 shows the average LFO debt per 1,000 residents of Seattle per year across racial and ethnic groups. Unlike Figure 2, which showed cases per capita, Figure 11 displays the average imposed LFO amount for each category of case, assuming it was evenly distributed across all residents of that group. Black Seattle residents receive more LFO sentences per capita than does any other group in the city for all categories of charges except criminal traffic offenses. Latinx residents receive more LFOs per capita than do Black Seattle residents for criminal traffic offenses.

Between 2000 and 2017, for every 1,000 Black residents in Seattle, SMC issued on average \$1767 in traffic infraction LFOs each year, \$148 in criminal traffic LFOs, \$77 in criminal nontraffic LFOs, and \$63 in DWLS3 LFOs. Note that American Indians / Alaska Natives and Latinx people are also disproportionately sentenced to SMC LFOs across many categories of violations. 
Figure 12. Ratio of adjusted SMC LFO debt per 1,000 residents by race/ethnicity relativeto white, 2014. Dashed line indicates equality.

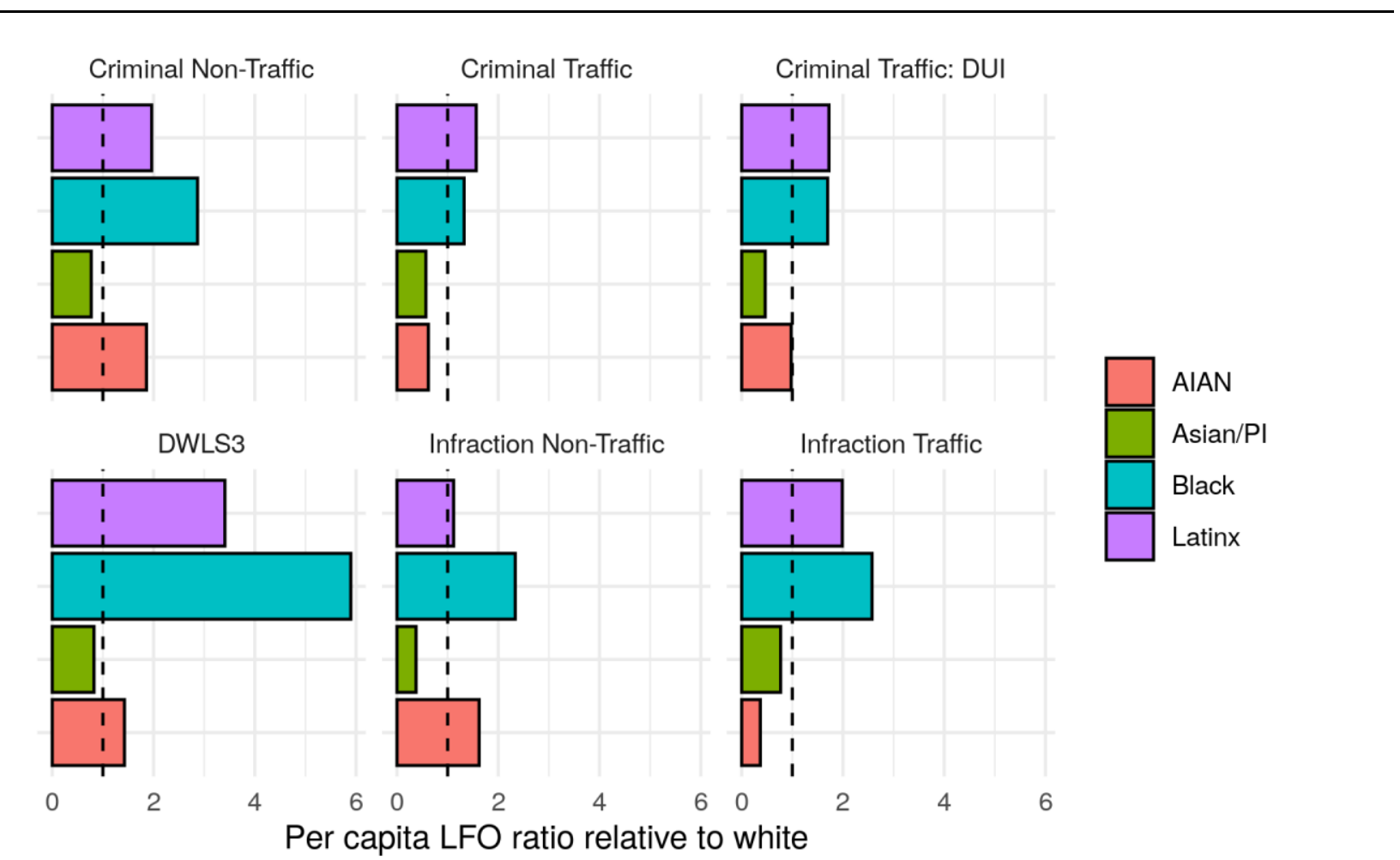

Figure 12 displays per capita sentencing values as ratios of the sentencing per capita for people of color in Seattle relative to the sentencing values White people received. This ratio provides a measure of disproportionality in LFO sentencing relative to population size by race/ethnicity. The dashed line at 1 indicates equity in LFO sentencing for White and non-White groups. Black people in Seattle are sentenced to DWLS3 LFOs at a rate nearly 6 times higher than the rate at which White people in Seattle are sentenced to DWLS3 LFOs. Latinx residents are sentenced to DWLS3 LFOs at a rate 3.4 times higher than the White sentencing rate. Black and Latinx Seattle residents are sentenced to LFO debt at higher rates than White Seattle residents for all categories of violations. American Indian / Alaska Native Seattle residents are sentenced to higher levels of debt than White residents for criminal non-traffic, infraction non-traffic, and DWLS3 than are White residents. There is a high degree of inequality measured as per capita debt load, but relatively low inequality measured as median adjusted court ordered debt. In sum, our exploration of racial disparities in traffic and non-traffic infractions illustrate a high degree of racial/ethnic disproportionality in both the case volume and ability to pay. 


\section{Comparison of the City of Seattle LFO process with other cities in WA State}

Below, we compare SMC LFO sentencing practices and caseloads to other municipal courts across Washington using data from the Washington Administrative Office of the Courts (AOC). Because coding systems for LFO obligation types differ across data systems, and municipal codes vary significantly across the state, we focus our comparison on aggregate LFO measures. Because of these complexities, and differences within courts across judges, it is difficult to directly compare the imposition of particular legal financial obligations. Instead, we focu s here on comparing how caseloads, average sentences, and total debt loads have varied across jurisdictions over time. We divide Washington municipalities into those with fewer than 10,000 residents, greater than 10,000 but fewer than 50,000 residents, greater than 50,000 but fewer than 75,000 residents, greater than 75,000 and fewer than 100,000 residents, more than 100,000 but fewer than 250,000 residents, and Seattle. Note that our AOC data only cover 2000 - 2014, while our SMC data cover 2000 - 2017. As such, we truncate the Seattle data to only include the years 2000 - 2014 to maximize comparability.

Figure 13. LFO debt ordered (adjusted) per 1,000 residents in Washington Municipal Courts, by population size of city

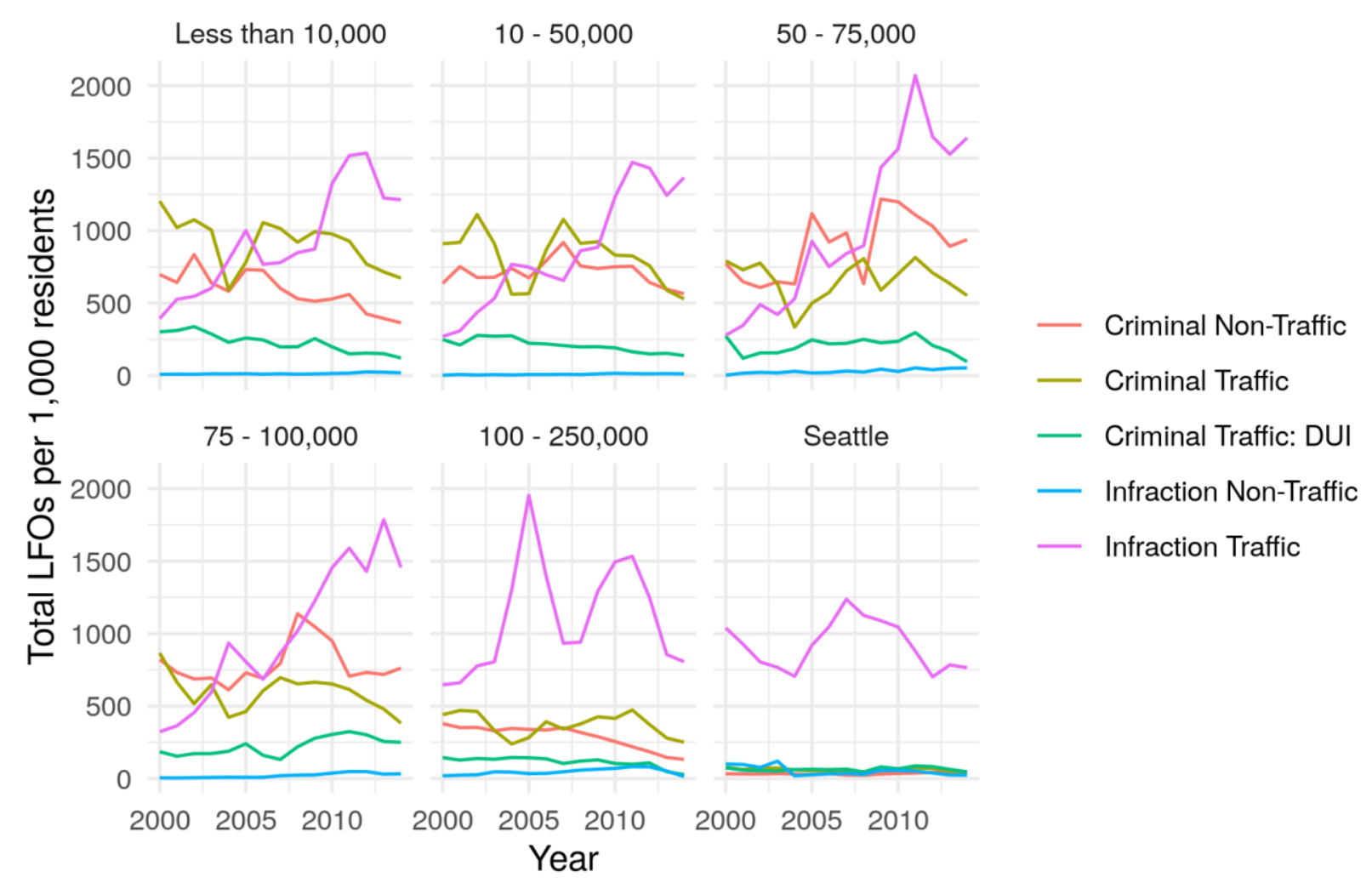

Figure 13 displays the median annual per capita LFO volume across Washington municipal courts. Note that LFO volume per capita is sensitive to case volume, sentenced amount, and population size. In all jurisdictions, non-traffic infractions make up a very small share of overall debt loads. Traffic infractions make up the bulk of debt in large cities, while criminal traffic and non-traffic cases make up a more substantial portion of total debt in mid-sized and smaller cities 
and towns. Despite having more cases per capita in recent years than other large Washington cities, the total LFO debt issued by SMC per capita for traffic infractions is similar to the total debt issued by other large city municipal courts in Washington in recent years.

Figure 14. LFO cases per 1,000 persons by case type and size of city population in Washington Municipal Courts, 2014

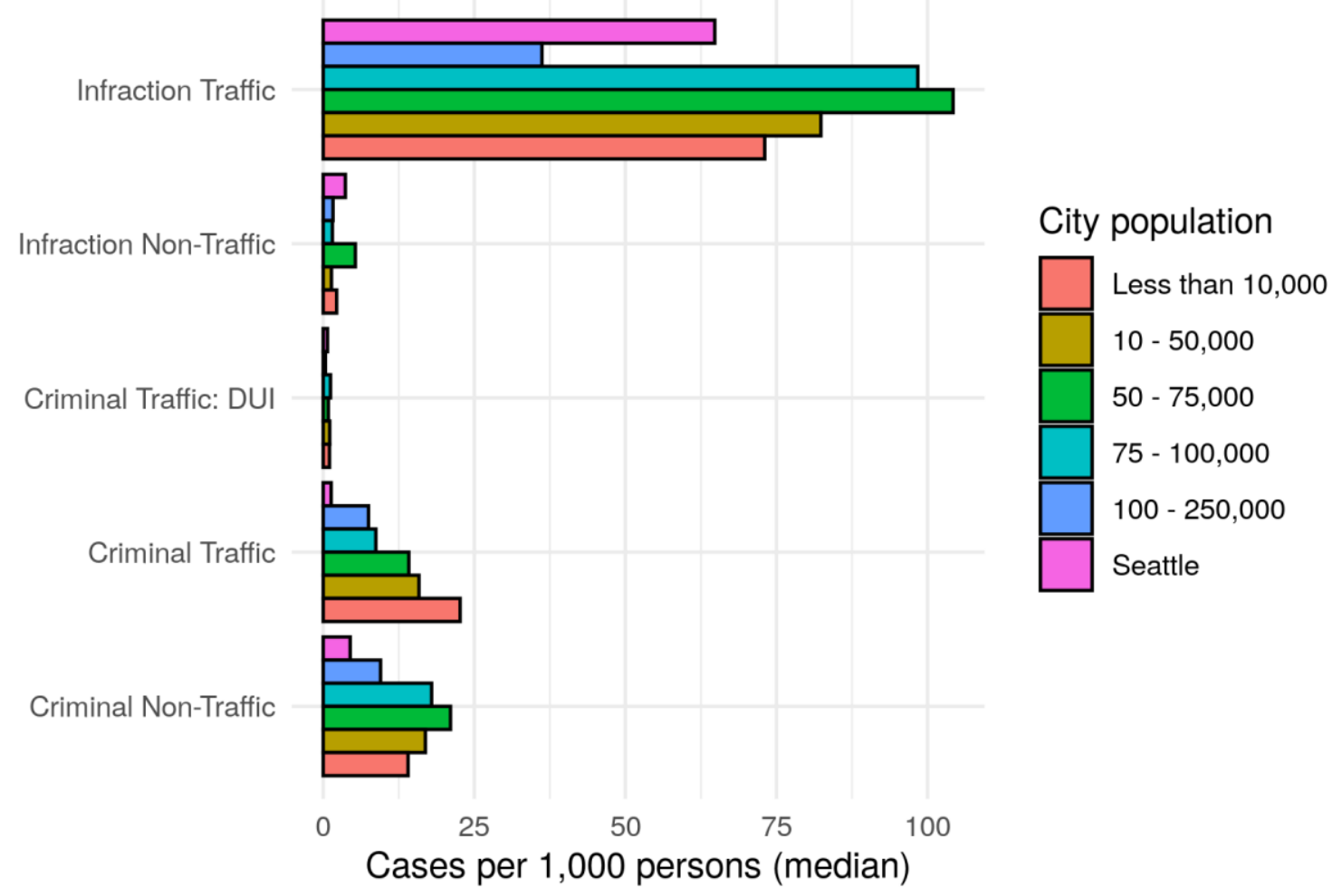

Figure 14 shows the population-adjusted case volume across cities in Washington. In 2014, Seattle's rate of traffic infraction LFO cases was higher than other large cities in Washington, like Tacoma, Spokane, and Everett. However, Seattle issued fewer traffic infractions per capita than did mid-sized cities and small municipalities. Seattle issued more non-traffic infractions per capita than all other classes of cities, with the exception of mid-sized cities $(50-75,000)$. DUI rates are similar across all city types. SMC, however, initiates far fewer criminal cases with LFOs than do other cities in Washington. For both traffic and non-traffic cases, SMC's case rate is much lower than other Washington cities.

Figure 15 displays the median adjusted LFO for each class of case in SMC and other Washington courts. SMC issues slightly lower median traffic infraction LFOs than does other municipal courts. The 2014 median in Seattle was \$212, compared to a median infraction LFO of $\$ 321$ in large cities (over 100,000), and \$266 in cities between 75 and 100,000 persons. SMC's median DUI LFOs after court adjustment are significantly lower than those in other municipal courts. In SMC, the median adjusted total LFO balance in 2014 was \$1193, compared to \$1965 in other large cities, and around \$2500 in mid-sized cities. For non-DUI criminal traffic cases, 
SMC LFO balances are similar to other municipal courts. For non-traffic criminal cases, SMC LFOs are much lower than those commonly imposed in other municipal courts .

Figure 15. Median LFO ordered (adjusted) in Washington Municipal Courts by population size of city, 2017

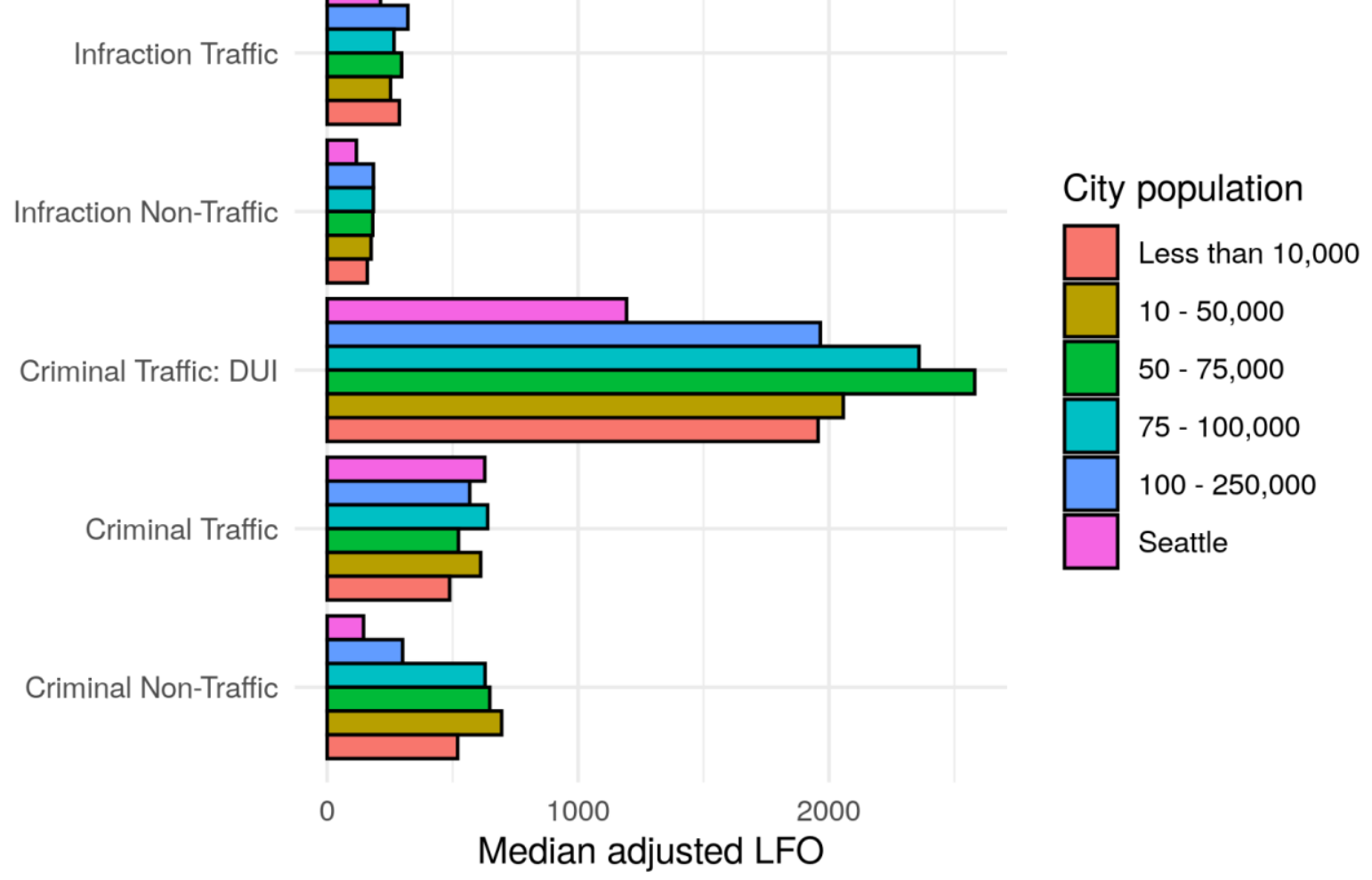




\section{Summary of Findings}

Our report examines four areas of interest: 1) the extent and characteristics of LFOs cited and sentenced in SMC, 2) the impact of SMC LFOs on individuals, 3) racial/ethnic differences in a subset of cases (traffic and non-traffic infraction), and 4) comparison of SMC to other municipal courts across Washington State.

In terms of the extent and characteristic of sentenced and outstanding LFO penalties in SMC, the total number of SMC LFO cases trended down from 2000-2017. Traffic infractions comprised the largest percentage of LFO cases in SMC, totaling $83 \%$ of all cases. Within all offense categories, people of color were ordered more money per 1,000 residents than were White people. SMC courts adjusted infractions related to LFOs (both traffic and non-traffic) more frequently than LFO cases involving criminal cases (non-traffic, traffic and DUI). In terms of the median LFOs originally sentenced, White people were sentenced/cited on average to the same amount or less than people of color. Black people were paying off LFO debt at lower rates than non-Black people

The issuance of LFOs has a positive correlation with the likelihood of subsequent incarceration. That is, our analysis examining the probability of incarceration with paid and unpaid LFO debt found that Black men and women are more likely to be incarcerated than White men and women post receiving a fine or fee citation or sentence. Black men who have paid off a $\$ 175$ LFO traffic infraction have a 3.2\% subsequently likelihood of incarceration compared to a $1.1 \%$ likelihood for White men. Black men with criminal non-traffic LFOs in the amount of $\$ 175$, and who have paid the costs off, have a probability of incarceration of $9.1 \%$ compared with similarly situated White men who have a probability of incarceration of $3.2 \%$. For those who have not paid off the debt they have a dramatically increased likelihood of incarceration, Black men have a probability of $26 \%$ and White men $10 \%$ of being incarcerated. Both for nonpayment of LFOs and even just the issuing of an LFO that has been paid, increases the likelihood of subsequent incarceration for individuals, but at a higher rate for Black men and women.

Along similar lines, in 2017, people of color overwhelmingly carried more LFO related debt in SMC than White people. This said, it appears that SMC has one of the least punitive sentencing schemas compared to other municipal courts in Washington State. SMC officials ordered the lowest amount of overall LFO sentencings/citations across Washington municipal courts. Seattle Municipal Court has the lowest mean ordered LFOs except within criminal traffic court, which are at par with other cities in the state.

In sum, it is clear that there are negative impacts resulting from LFOs imposed by Seattle Municipal Courts, police and traffic officials. These consequences are disproportionately borne by people of color. The consequences we examined include length of court debt and likelihood of incarceration post imposition of debt. Such consequences can have further triggering effects such as the loss of driver's licenses, garnishment of needed wages to support children and families, the issuing of warrants and further incarceration. 


\section{Policy Implications}

Despite comparatively imposing LFO debts at lower rates than other cities in Washington, Seattle Municipal Courts still engage in a system of monetary sanctions that leads to disproportionate and negative outcomes for Seattle residents, and in particular, people of color. The intended outcome of future policies should be to ensure that individuals who come into contact with the criminal justice system are not permanently disadvantaged by legal debt.

There are several policy implications that emerge from our analysis. First, we suggest that SMC engage in a broader penological discussion with judges and stakeholders in Washington State about the aim of sentencing and citing people for law violations. What is the aim of sentencing fines and fees to people who violate laws? Is there a way to hold people accountable for violations even when they cannot afford the fines and fees? Are there alternatives to LFO sentences that could possibly improve public safely and to hold people accountable? Alternatives should make sure not to reinforce existing inequalities, for example, some people will be able to pay if they have means, while others will be sentenced to work crews. Thoughtful conversations about court sentencing options that include opportunities for individuals to better themselves through furthering education, drug and alcohol treatment, employment readiness, mental health care and community based service should be considered.

Furthermore, policy makers, practitioners and officials should recognize that the system of monetary sanctions has multiple discretion points, a large number of stakeholders, and a large set of costs. For example, SMC judges must manage the traffic citations that police and parking enforcement officers issue. The bulk of the LFOs cases examined in this study were initiated from such citations. Within this context, SMC judges can only adjust the amounts within existing statutes.

More immediate policy changes could include:

- SMC judges should continue to assess individuals' abilities to pay in all circumstances when sentencing LFOs. Judges do appear to be adjusting discretionary fines and fees, where they can, upon reconsideration of sentenced amounts.

- Judges should continue to waive discretionary costs when people indicate they have little to no ability to pay.

- Policies at the state and local should interrogate the necessity for add-on financial penalties such as interest, time payment set-up fee, JIS fee, default penalties, deferred finding administration fee. These costs may inhibit or distract payments towards the fines and restitution.

- State policy should decouple non-payment from criminal matters and suspension of driver's licenses. Our analysis highlights huge racial disproportionality in the conviction of DWLS in the third degree to Black men in Seattle. We suggest state policy eliminate driver's license suspensions that result from nonpayment of citations, fines and fees and in turn lead to DWLS in the third degree convictions. 
- State and local jurisdictions should conduct regular monitoring and analysis of LFO sentencing and collections. Much of our analysis implies the need for local and state court systems to monitor the impact of LFOs on communities of color. SB 1783, as it currently stands, is silent on the issue of racial disparities. Local and state policy should require courts to monitor the impacts of this legal financial obligation on people of color. No punishment schema should produce disproportionate effects for varying populations. Further analyses should be conducted to examine individual level effects including poverty status and race on outcomes such as length of debt burden and subsequent incarceration. This effort would require improving and ensuring consistency in data collection practices across counties and municipalities.

Our findings are consistent with research that suggests the current practice of imposing LFOs has permanently tethered many who are unable to pay to the criminal justice system for a long period of time. ${ }^{x}$ The above policy suggestions recognize that poor individuals and people of color experience the criminal justice system differently in a way that limits their full participation in society. These policy recommendations would help address the disproportionality of the effects of LFOs we found in this study. We suggest justice officials work collaboratively to further public safety and enforce a penalty structure that does not lead to racial and economic inequalities such as long-term debt burdens and increased likelihood of incarceration. 


\section{Appendix A. Examination of Seattle Municipal Court Observational Data}

In conjunction with the SMC data analysis project, Alexes Harris was asked to review Seattle Municipal Court observational data she has been collecting as part of a larger eight state study funded by Arnold Ventures. The aim was to examine the extent to which ability to pay hearings were occurring at the time of LFO sentencing. We have a total of 200 hearing observations in SMC. The RA recorded a set of observational codes on a "court observation" coding sheet. A protocol used across court observations in the eight states of foci. Table 1 outlines the characteristics of the court type, offenses observed and characteristics of defendants before the court. In addition, the RA recorded hand written field notes on the types of discussions occurring between judges, attorneys and people brought before the court.

Unfortunately, only eight of the hearings the RA randomly observed involved sentencing hearings. As such, not much can be said about the frequency of whether or not ability to pay hearings were being held by SMC judges. Other hearings the RA observed included review hearings, cases involving bench warrants, competency, continuances, DUI pretrial, DV review, mental health review, pretrial, probation review and probation revocation. I also reviewed the field notes (searched for terms "pay" "ability to pay" and "fine" or "fee") no formal "hearings" or discussion of ability to pay.

Interestingly, I found in the text of the field notes frequent discussions between judges, attorneys and defendants about LFO sentences and other court imposed punishments with costs. Much of the discourse focused on people's inability to make any or regular payments. These discussions involved issues related to payment plans, the court imposed $\$ 25$ community service fee (frequently waived), the $\$ 42$ criminal conviction fee and probation costs. Several conversations focused on people's inability to find or make payments for court imposed alcohol or drug assessment and treatment. Frequently, people said they could not pay for this mandated sentence. 
Table A.1. Summary of SMC Court Observations, 2017-2018 ( $N=200$ hearings).

\begin{tabular}{|c|c|c|}
\hline & Number & Percentage \\
\hline \multicolumn{3}{|l|}{ Court Type } \\
\hline Criminal traffic & 73 & 36 \\
\hline Gross misdemeanor & 119 & 59 \\
\hline Misdemeanor criminal traffic & 13 & 6 \\
\hline \multicolumn{3}{|l|}{ Type of offense } \\
\hline Assault & 28 & 14 \\
\hline criminal trespass & 10 & 4 \\
\hline driving with suspended license & 9 & 4 \\
\hline DUI & 7 & 3.5 \\
\hline Domestic violence & 7 & 3.5 \\
\hline Presence under influence of intoxicants & 44 & 22 \\
\hline Reckless driving & 13 & 6 \\
\hline Sexual exploitation & 7 & 3.5 \\
\hline Theft & 28 & 14 \\
\hline \multicolumn{3}{|l|}{ Sex } \\
\hline Women & 52 & 26 \\
\hline Men & 148 & 74 \\
\hline \multicolumn{3}{|l|}{ Race/Ethnicity } \\
\hline Asian & 7 & 3 \\
\hline Black & 57 & 28 \\
\hline Latinx & 24 & 12 \\
\hline Middle Eastern & 4 & 2 \\
\hline Native American & 1 & 0.5 \\
\hline White & 79 & 39 \\
\hline Unknown & 7 & 3 \\
\hline Was not present & 22 & 11 \\
\hline \multicolumn{3}{|l|}{ Custody Status } \\
\hline In & 39 & 20 \\
\hline Out & 161 & 80 \\
\hline
\end{tabular}


An Analysis of Court Imposed Monetary Sanctions in Seattle Municipal Courts

\section{Endnotes}

${ }^{\mathrm{i}}$ For example see Washington State RCW RCW 9.94A.777

https://www.courts.wa.gov/content/manuals/Superior\%20Court\%20LFOs.pdf

ii Alexes Harris, Heather Evans \& Katherine Beckett. Drawing Blood from Stones: Legal Debt and Social Inequality in the Contemporary U.S. American Journal Of Sociology 115(6): 175599 (2010). In for a Penny: The Rise of America's New Debtors Prison. ACLU (2010). Criminal Justice Debt: A Barrier to Re-entry. (2010). Karin D. Martin, et al., Monetary Sanctions: Legal Financial Obligations in U.S. Systems of Justice, 1 Annual Review Of Criminology (2018).; Brittany Friedman \& Mary Pattillo, Statutory Inequality: The Logics of Monetary Sanctions in Sate Law, 5 RSF: The Russell Sage Foundation Journal Of The Social Sciences (2019). Beth Colgan. Wealth-Based Penal Disenfranchisement. 72 Vanderbilt Law Review. (2019).

iii Alexes Harris, Heather Evans \& Katherine Beckett, Courtesy Stigma and Monetary Sanctions: Toward a Socio-Cultural Theory of Punishment. American Sociological Review 76(2): 131(2011). Alexes Harris, A Pound of Flesh: Monetary Sanctions as a Punishment for the Poor. (2016). Alex Piquero and Wesley Jennings. Research Note: Justice System-Imposed Financial Penalties Increase the Likelihood of Recidivism in a Sample of Adolescent Offenders. Youth Violence \& Juvenile Justice 15(3):1-16. (2017). Leslie Paik \& Chiara Packard. Impact of Juvenile Justice Fines and Fees on Family Life: Case Study in Dane County, WI. Philadelphia, PA: Juvenile Law Center. (2019).

iv Harris et. al, (2010). Mary Fainsod Katzenstein \& Maureen R. Waller. Axing the Poor: Incarceration, Poverty Governance, and the Seizure of Family Resources. 12 Perspectives On Politics (2015). April D. Fernandes, et al., Monetary Sanctions: A Review of Revenue Generation, Legal Challenges, and Reform, 15 Annual Review Of Law And Social Sciences (2019). Alexes Harris, Tyler Smith and Emmi Obara. Justice "Cost Points:" Examination of Privatization within Public Systems of Justice. Criminology \& Public Policy (2019). Joshua Page, Victoria Piehowski, and Joe Soss. A Debt of Care: Commercial Bail and the Gendered Logic of Criminal Justice Predation. RSF: The Russell Sage Foundation Journal Of The Social Sciences 5(1): 150-72. DOI: 10.7758/RSF.2019.5.1.07 (2019)

${ }^{\mathrm{v}} \underline{\text { https://apps.leg.wa.gov/rcw/default.aspx?cite=9.94A.760 }}$

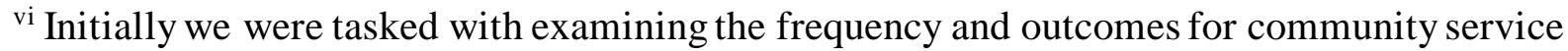
conversions, however there was no way to identify or track such cases. A suggestion for future court data collection efforts would be to create a data element that captures when a judge converts individuals conversation of LFO dollars to community service hours. Given the data set we used we are just not able to determine such instances.

${ }^{\text {vii }} \underline{\text { http://www.courts.wa.gov/jislink/?fa=jislink.jis }}$

viii Imai, K., \& Khanna, K. (2016). Improving Ecological Inference by Predicting Individual Ethnicity from Voter Registration Records. Political Analysis, 24(2), 263-272.

doi:10.1093/pan/mpw001 
An Analysis of Court Imposed Monetary Sanctions in Seattle Municipal Courts

ix “Driving While License Invalidated” RCW 46.20.342.

https://apps.leg.wa.gov/rcw/default.aspx?cite $=46.20 .342$

${ }^{\mathrm{x}}$ Harris, Alexes. 2016. A Pound of Flesh: Monetary Sanctions as a Punishment for the Poor. Russell Sage, NYC. 